Article

\title{
Crystallization of Diamond from Melts of Europium Salts
}

\author{
Yuri M. Borzdov ${ }^{1}$, Alexander F. Khokhryakov ${ }^{1,2, *}$, Igor N. Kupriyanov ${ }^{1}$, Denis V. Nechaev ${ }^{1}$ \\ and Yuri N. Palyanov 1,2 \\ 1 Sobolev Institute of Geology and Mineralogy SB RAS, Koptyug ave. 3, 630090 Novosibirsk, Russia; \\ borzdov@igm.nsc.ru (Y.M.B.); spectra@igm.nsc.ru (I.N.K.); nechaev@igm.nsc.ru (D.V.N.); \\ palyanov@igm.nsc.ru (Y.N.P.) \\ 2 Department of Geology and Geophysics, Novosibirsk State University, 630090 Novosibirsk, Russia \\ * Correspondence: khokhr@igm.nsc.ru; Tel.: +7-383-330-7501
}

Received: 17 April 2020; Accepted: 6 May 2020; Published: 7 May 2020

\begin{abstract}
Diamond crystallization in melts of europium salts $\left(\mathrm{Eu}_{2}\left(\mathrm{C}_{2} \mathrm{O}_{4}\right)_{3} \cdot 10 \mathrm{H}_{2} \mathrm{O}, \mathrm{Eu}_{2}\left(\mathrm{CO}_{3}\right)_{3} \cdot 3 \mathrm{H}_{2} \mathrm{O}\right.$, $\left.\mathrm{EuCl}_{3}, \mathrm{EuF}_{3}, \mathrm{EuF}_{2}\right)$ at $7.8 \mathrm{GPa}$ and in a temperature range of $1800-2000{ }^{\circ} \mathrm{C}$ was studied for the first time. Diamond growth on seed crystals was realized at a temperature of $2000{ }^{\circ} \mathrm{C}$. Spontaneous diamond nucleation at these parameters was observed only in an Eu oxalate melt. The maximum growth rate in the europium oxalate melt was $22.5 \mu \mathrm{m} / \mathrm{h}$ on the $\{100\}$ faces and $12.5 \mu \mathrm{m} / \mathrm{h}$ on the $\{111\}$ faces. The diamond formation intensity in the tested systems was found to decrease in the following sequence: $\mathrm{Eu}_{2}\left(\mathrm{C}_{2} \mathrm{O}_{4}\right)_{3} \cdot 10 \mathrm{H}_{2} \mathrm{O}>\mathrm{Eu}_{2}\left(\mathrm{CO}_{3}\right)_{3} \cdot 3 \mathrm{H}_{2} \mathrm{O}>\mathrm{EuF}_{3}>\mathrm{EuF}_{2}=\mathrm{EuCl}_{3}$. Diamond crystallization occurred in the region of stable octahedral growth in melts of $\mathrm{Eu}^{3+}$ salts and in the region of cubo-octahedral growth in an $\mathrm{EuF}_{2}$ melt. The microrelief of faces was characterized by specific features, depending on the system composition and diamond growth rate. In parallel with diamond growth, the formation of metastable graphite in the form of independent crystals and inclusions in diamond was observed. From the spectroscopic characterization, it was found that diamonds synthesized from Eu oxalate contain relatively high concentrations of nitrogen (about 1000-1200 ppm) and show weak PL features due to inclusions of Eu-containing species.
\end{abstract}

Keywords: diamond; high-pressure; high temperature; crystallization; crystal morphology; rare-earth ions; defects; characterization

\section{Introduction}

Lately, the investigation of the optical properties of rare-earth (RE) ions in various crystalline matrices has attracted the interest of many researchers. Diamond, due to its unique electrophysical, thermophysical, optical and mechanical properties, is an ideal matrix for various optically active defects, in particular for RE ions. Rare-earth ions have unique optical properties, in particular narrow-band luminescence, with a long decay time and an exceptionally long nuclear spin coherence time $[1,2]$. A combination of the extreme properties of diamonds and the optical and magnetic characteristics of REs makes diamonds containing luminescent RE ions promising materials in various fields of modern technology. The technological interest in rare-earth luminescence is quite wide and includes telecommunications, laser materials, data storage, bio-medical applications and many other fields of application. In this regard, of considerable interest is the search for new systems for diamond growth, which will involve the doping of diamonds with RE ions. However, the problem of producing diamond crystals doped with rare-earth elements remains unresolved.

The first attempts to dope diamond with europium $\left(\mathrm{Eu}^{3+}\right)$-containing nanoparticles were undertaken using a multi-step chemical vapor deposition method (CVD) [3,4]. An alternative method 
was to obtained diamond-rare-earth composite material with luminescent $\mathrm{EuF}_{3}$ nanoparticles [5]. The doping of diamond with single rare-earth ions using CVD has not been successful yet. The first results on polycrystalline diamond synthesis at pressure of 8-9 GPa and temperature of $1600-2200{ }^{\circ} \mathrm{C}$ in RE-carbon systems were reported by Ekimov et al. [6] However, the spectroscopic characterization of the synthesized diamonds did not reveal optical centers associated with rare-earth elements. Recently, we have tested magnesium-based systems containing rare-earth elements [7] and their oxides [8]. The magnesium-based systems are of interest because they exhibit very high diamond crystallization rates in a kinetically controlled mode. Magnesium was shown to promote synthesis of nitrogen-free crystals with optical quality acceptable for spectroscopic studies $[9,10]$. In $\mathrm{Mg}+\mathrm{R}_{2} \mathrm{O}_{3}+\mathrm{C}$ systems (where $\mathrm{R}=\mathrm{Nd}, \mathrm{Sm}, \mathrm{Eu}, \mathrm{Tb}, \mathrm{Dy}, \mathrm{Ho}, \mathrm{Er}, \mathrm{Tm}$, and $\mathrm{Yb}$ ) at $7.8 \mathrm{GPa}$ and $1800{ }^{\circ} \mathrm{C}$, the addition of RE oxides in an amount of $10 \mathrm{wt} . \%$ was found to have no significant effect on diamond crystallization relative to the $\mathrm{Mg}-\mathrm{C}$ system [8]. Diamond crystals synthesized with $20 \mathrm{wt} . \%-30 \mathrm{wt} . \% \mathrm{Sm}_{2} \mathrm{O}_{3}$ additives revealed a photoluminescence signal resembling the emission spectrum of $\mathrm{Sm}^{3+}$ ions. The results of diamond crystallization at similar parameters in $\mathrm{Mg}+\mathrm{REM}+\mathrm{C}$ systems $(\mathrm{REM}=\mathrm{Sc}, \mathrm{Y}, \mathrm{La}, \mathrm{Pr}, \mathrm{Nd}, \mathrm{Dy}$, and $\mathrm{Yb}$ ) unambiguously indicate an inhibitory effect of rare-earth metals [7]. In addition, diamonds produced with $\mathrm{Y}, \mathrm{Nd}$, and $\mathrm{Yb}$ additives demonstrated a number of new photoluminescent characteristics that may be associated with specific defects causing diamond growth inhibition.

In the present work, diamond crystallization in melts of europium salts was investigated for the first time. This study continues our investigation of the RE influence on diamond synthesis at high $\mathrm{P}$ and $\mathrm{T}$ parameters and the possible formation of optical centers in crystals, which are associated with rare-earth elements. The choice of Eu oxalate, Eu carbonate, and Eu halides as potential solvent-catalysts of diamond synthesis is based on our previous experience of successful diamond synthesis and growth in alkali and alkaline earth metal salts [11-14].

\section{Materials and Methods}

Experiments were performed at a pressure of $7.8 \mathrm{GPa}$, a temperature of $1800-2000{ }^{\circ} \mathrm{C}$, and a runs time of 60 to $120 \mathrm{~min}$ using a split-sphere multi-anvil high-pressure apparatus (Table 1). The experimental technique, design of high-pressure cell, and calibrations of pressure and temperature were described in our previous works $[9,10,15]$. The choice of experimental parameters was based on our studies of diamond crystallization in magnesium-RE systems $[7,8]$. Graphite rods (purity of 99.99\%) and europium salts (purity of 99.99\%) were used as starting materials (Table 1). Graphite rods were processed into thick-walled $(1.5 \mathrm{~mm})$ capsules, with an outer diameter of $6.9 \mathrm{~mm}$ and a height of $6.5 \mathrm{~mm}$. Europium salts were encapsulated into graphite capsules. Synthetic industrial grade diamonds SDA100 $+0.4-0.5 \mathrm{~mm}$ in size were used as seed crystals. The seed crystals had a cuboctahedral shape and flat $\{111\}$ and $\{100\}$ faces. According to the manufacturer's specifications, they contained trace amounts of nitrogen, nickel and cobalt impurities. In each experiment four diamond seed crystals were used, which were placed at the interface between the graphite capsule and Eu salts. In all experiments, graphite capsules were wrapped outside, with $0.1 \mathrm{~mm}$ thick Mo foil that protected the capsule contents from external influences. Before the study, diamonds were purified from experimental products by a hot mixture of $\mathrm{HNO}_{3}$ and $\mathrm{HCl}$ acids (1:3 volume ratio). Then, diamonds were processed in a hot mixture of concentrated $\mathrm{H}_{2} \mathrm{SO}_{4}$ and a $30 \%$ aqueous solution of $\mathrm{K}_{2} \mathrm{Cr}_{2} \mathrm{O}_{7}(3: 2$ volume ratio), to remove graphite and possible organic pollutants. Diamonds were washed in hot distilled water after each acid treatment.

Diamond crystals were studied using optical microscopy on a Carl Zeiss Axio Imager Z2m microscope (Carl Zeiss Microscopy, Jena, Germany). The differential-interference contrast (DIC) method was used to enhance the contrast of faces' relief images. Scanning electron microscopy (SEM) of crystals was performed on a Tescan MIRA3 LMU microscope (Tescan, Brno, Czech Republic) at the Analytical Center for the Multi-Elemental and Isotope Research of the Siberian Branch of the Russian Academy of Sciences. Spectroscopic study of diamond crystals was carried out using infrared (IR) absorption and photoluminescence (PL). IR spectra were recorded using a Bruker Vertex 70 
Fourier transform infrared (FTIR) spectrometer, fitted with a Hyperion 2000 microscope (Bruker Optics, Ettlingen, Germany). PL spectra were measured using a custom-built setup based on a Horiba JY iHR320 monochromator equipped with a Syncerity CCD detector (Horiba Jobin Yvon S.A.S., Lonjumeau, France). Photoluminescence was excited using a $395 \mathrm{~nm}$ diode laser (Omicron-Laserage Laserprodukte $\mathrm{GmbH}$, Rodgau-Dudenhofen, Germany). A Linkam FTIR600 heating/freezing stage (Linkam Scientific Instruments, Tadworth, UK) was used for the low-temperature measurements.

Table 1. Experimental conditions and results.

\begin{tabular}{|c|c|c|c|c|c|c|c|c|}
\hline \multirow{2}{*}{ Run No } & \multirow{2}{*}{ Composition } & \multirow{2}{*}{$\mathbf{P}, \mathrm{GPa}$} & \multirow{2}{*}{$\mathrm{T},{ }^{\circ} \mathrm{C}$} & \multirow{2}{*}{ Time, min } & \multicolumn{2}{|c|}{ Growth on Seed, $\mu \mathrm{m} *$} & \multirow{2}{*}{$\begin{array}{c}\text { Diamond } \\
\text { Nucleation, } \mu \mathrm{m} *\end{array}$} & \multirow{2}{*}{$\begin{array}{l}\text { Metastable } \\
\text { Graphite }\end{array}$} \\
\hline & & & & & $\{111\}$ & $\{100\}$ & & \\
\hline ES-1 & $\mathrm{EuCl}_{3}$ & 7.8 & 1800 & 60 & - & - & - & + \\
\hline ES-2 & $\mathrm{EuCl}_{3}$ & 7.8 & 1800 & 120 & - & - & - & + \\
\hline ES-3 & $\mathrm{EuCl}_{3}$ & 7.8 & 2000 & 120 & 2 & 4 & - & + \\
\hline ES-4 & $\mathrm{Eu}_{2}\left(\mathrm{CO}_{3}\right)_{3} \cdot 3 \mathrm{H}_{2} \mathrm{O}$ & 7.8 & 1800 & 60 & - & - & - & + \\
\hline ES-5 & $\mathrm{Eu}_{2}\left(\mathrm{CO}_{3}\right)_{3} \cdot 3 \mathrm{H}_{2} \mathrm{O}$ & 7.8 & 1800 & 120 & - & - & - & + \\
\hline Es-6 & $\mathrm{Eu}_{2}\left(\mathrm{CO}_{3}\right)_{3} \cdot 3 \mathrm{H}_{2} \mathrm{O}$ & 7.8 & 2000 & 120 & 11 & 20 & - & + \\
\hline ES-7 & $\mathrm{Eu}_{2}\left(\mathrm{C}_{2} \mathrm{O}_{4}\right)_{3} \cdot 10 \mathrm{H}_{2} \mathrm{O}$ & 7.8 & 2000 & 60 & 12 & 23 & - & + \\
\hline ES-8 & $\mathrm{Eu}_{2}\left(\mathrm{C}_{2} \mathrm{O}_{4}\right)_{3} \cdot 10 \mathrm{H}_{2} \mathrm{O}$ & 7.8 & 2000 & 120 & 25 & 45 & 25 & + \\
\hline ES-9 & $\mathrm{EuF}_{2}$ & 7.8 & 1800 & 60 & - & - & - & - \\
\hline ES-10 & $\mathrm{EuF}_{2}$ & 7.8 & 2000 & 120 & 3 & 4 & - & - \\
\hline ES-11 & $\mathrm{EuF}_{3}$ & 7.8 & 1800 & 60 & - & - & - & + \\
\hline ES-12 & $\mathrm{EuF}_{3}$ & 7.8 & 2000 & 120 & 4 & 7 & - & + \\
\hline
\end{tabular}

*The maximum thickness of the overgrown layer on the $\{111\}$ and $\{100\}$ faces of the seed crystals and the maximum sizes of spontaneous diamond crystals are indicated.

\section{Results and Discussion}

\subsection{Diamond Crystallization}

The choice of starting experimental parameters was based on our studies of diamond crystallization in magnesium-RE systems $[7,8]$. Therefore, the first experiments on diamond synthesis in molten europium salts were carried out at a pressure of $7.8 \mathrm{GPa}$, a temperature of $1800^{\circ} \mathrm{C}$, and a run duration of $60 \mathrm{~min}$. The experimental results demonstrated the lack of diamond synthesis and no growth on seed crystals at these parameters. In all experiments, metastable graphite was detected (Table 1). An increase in the run time to $120 \mathrm{~min}$ at $1800{ }^{\circ} \mathrm{C}$ in $\mathrm{EuCl}_{3}+\mathrm{C}$ and $\mathrm{Eu}_{2}\left(\mathrm{CO}_{3}\right)_{3} \cdot 3 \mathrm{H}_{2} \mathrm{O}+\mathrm{C}$ systems (runs ES-2 and ES-6) did not result in diamond synthesis and growth on seeds. For this reason, the experimental temperature was elevated to $2000{ }^{\circ} \mathrm{C}$, with a run time of $120 \mathrm{~min}$ being unchanged. In all experiments at $2000^{\circ} \mathrm{C}$ in europium salts, there was diamond growth on the $\{111\}$ and $\{100\}$ faces of seed crystals (Table 1). In this case, the thickness of newly formed diamond layers differed significantly. There was no problem in determining the thickness of overgrown layers. After the experiment, seed crystals were found to be pressed into the graphite capsule to varying degrees. Growth of the newly formed diamond occurred only towards melts of RE salts, and the faces of a seed diamond in graphite remained almost unchanged or were slightly dissolved. As a result, a distinct step in the diamond relief was formed at the graphite-salt melt salt boundary. This is most clearly seen in the case of significant diamond growth that occurred in the europium oxalate melt (Figure 1a). Most of the diamond seed crystal shown in Figure 1a was located in the graphite capsule. Overgrowth of the newly formed diamond occurred on a small part of the seed, which contacted the molten salt. Table 1 shows the thicknesses of overgrown diamond layers on the $\{100\}$ and $\{111\}$ faces of seed crystals, which may be used to assess the diamond growth rates. The highest growth rate occurred in a europium oxalate melt $\left(\mathrm{Eu}_{2}\left(\mathrm{C}_{2} \mathrm{O}_{4}\right)_{3} \cdot 10 \mathrm{H}_{2} \mathrm{O}\right): 22.5 \mu \mathrm{m} / \mathrm{h}$ on the $\{100\}$ faces and $12.5 \mu \mathrm{m} / \mathrm{h}$ on the $\{111\}$ faces (run ES-8). Additionally, it was the only experiment where spontaneous crystals were produced. Spontaneous crystals of up to $25 \mu \mathrm{m}$ in size had an octahedral shape. Spontaneous diamonds occurred both on seed crystals (Figure 1c,d) and on the walls of the capsule (Figure 1e,f). Separate not attached diamond crystals (diamond nucleation in the melt) were not detected. 

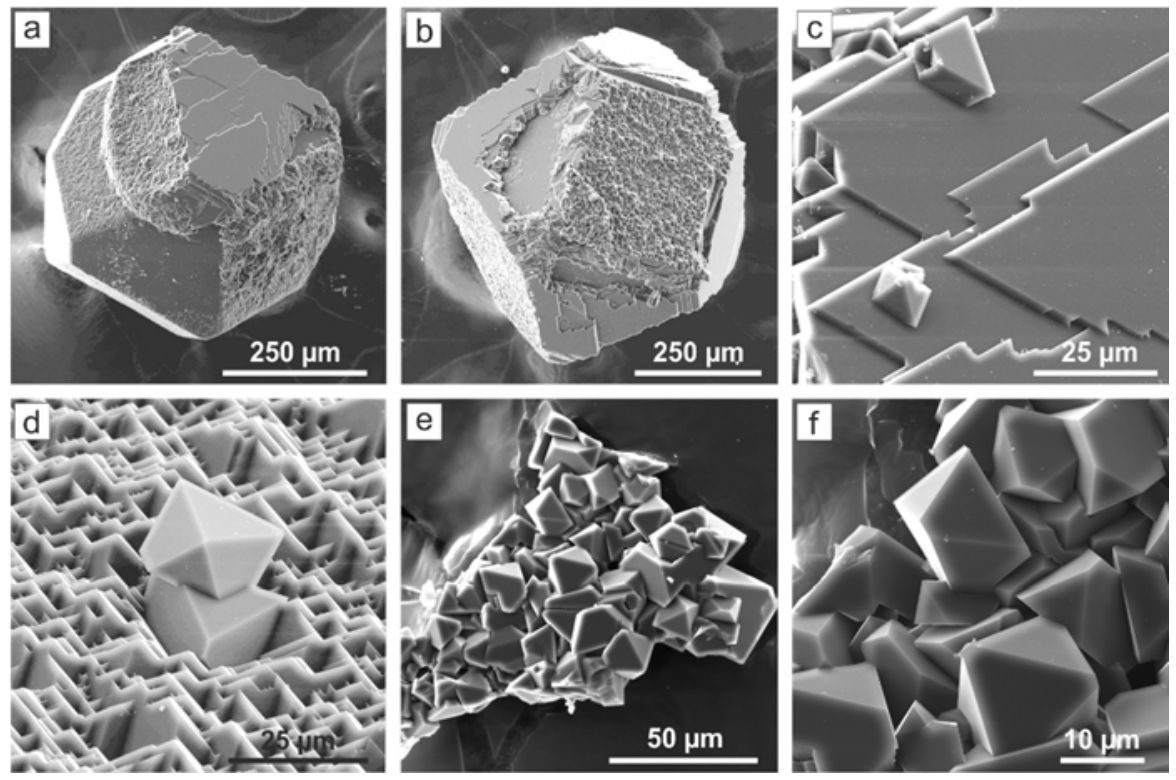

Figure 1. SEM micrographs of diamonds after run with Eu oxalate melt (run ES-8): (a,b) seed crystals with overgrown diamond layers; (c) $\{111\}$ face with macrolayers of growth and spontaneous diamond crystals; (d) $\{100\}$ face with spontaneous diamond crystals; (e,f) intergrowth of spontaneous diamond crystals.

Less intensive diamond growth occurred on seed crystals in an aqueous Eu carbonate melt (Figure 2). The growth rate was no more than $10 \mu \mathrm{m} / \mathrm{h}$ on the $\{100\}$ faces and about $5.5 \mu \mathrm{m} / \mathrm{h}$ on the $\{111\}$ faces. The lowest diamond growth rate was detected in experiments with $\mathrm{EuCl}_{3}$ (run ES-3) and $\mathrm{EuF}_{2}$ (run ES-10) melts. The diamond growth rate in these experiments was only $2 \mu \mathrm{m} / \mathrm{h}$ on the $\{100\}$ faces and $1.0-1.5 \mu \mathrm{m} / \mathrm{h}$ on the $\{111\}$ faces. Thus, the diamond formation intensity in the studied systems decreases in the following sequence: $\mathrm{Eu}_{2}\left(\mathrm{C}_{2} \mathrm{O}_{4}\right)_{3} \cdot 10 \mathrm{H}_{2} \mathrm{O}>\mathrm{Eu}_{2}\left(\mathrm{CO}_{3}\right)_{3} \cdot 3 \mathrm{H}_{2} \mathrm{O}>\mathrm{EuF}_{3}>\mathrm{EuF}_{2}=\mathrm{EuCl}_{3}$ at $\mathrm{P}=7.8 \mathrm{GPa}$ and $\mathrm{T}=2000^{\circ} \mathrm{C}$. The identified series of abilities of Eu salts to diamond formation is consistent with the previously identified patterns for alkali metal compounds.

For example, Palyanov et al. [11,14] demonstrated that the maximum diamond growth rates in alkali carbonate melts at $\mathrm{P}=5.7-7.5 \mathrm{GPa}$ and $\mathrm{T}=1200-1700^{\circ} \mathrm{C}$ occurred in the presence of oxalate. In water-carbonate systems, the growth rate was significantly reduced. In $\mathrm{KCl}$ melts, the minimum growth rates were detected at significantly higher temperatures only $[13,16]$. It should also be noted that the observed diamond growth rates in RE salt melts are significantly lower than those obtained previously in magnesium-based systems in the presence of REs. For example, diamond growth rates in the $\mathrm{Mg}+\mathrm{Sm}_{2} \mathrm{O}_{3}+\mathrm{C}$ system at a temperature of $1800{ }^{\circ} \mathrm{C}$ ranged from $1.65 \mathrm{~mm} / \mathrm{h}$ (at $10 \mathrm{wt} . \% \mathrm{Sm}_{2} \mathrm{O}_{3}$ ) to $0.3 \mathrm{~mm} / \mathrm{h}$ (at $30 \mathrm{wt} . \% \mathrm{Sm}_{2} \mathrm{O}_{3}$ ) [8]. In Mg-REM-C systems, the minimum growth rate of $0.5 \mathrm{~mm} / \mathrm{h}$ (Mg90Yb10+C system) [7] is almost two orders of magnitude higher than the diamond growth rates in molten Eu salts. Apparently, in magnesium-based systems, magnesium primarily contributed to the intensity of diamond formation.

However, unambiguous diamond growth was detected in all the tested systems with europium salts. In all experiments with $\mathrm{Eu}^{3+}$ salts, the ratio of growth rates on the $\{100\}$ and $\{111\}$ faces, $V_{(100)} / V_{(111)}$, ranges from 1.75 to 2.0. According to geometric constructions, the formation of an octahedral crystal without $\{100\}$ faces requires the $\mathrm{V}_{(100)} / \mathrm{V}_{(111)}$ ratio of speeds to be more than 1.73. Therefore, diamond crystallization in molten $\mathrm{Eu}^{3+}$ salts occurred in the region of stable octahedral growth. Indeed, spontaneous diamond crystals produced in an $\mathrm{Eu}_{2}\left(\mathrm{C}_{2} \mathrm{O}_{4}\right)_{3} \cdot 10 \mathrm{H}_{2} \mathrm{O}$ melt also have an octahedral shape (run ES-8). The rate ratio is also reflected in the microrelief of $\{100\}$ and $\{111\}$ faces. The $\{100\}$ faces had rough surfaces formed by tetragonal pyramids with octahedral faceting; no flat sites of the $\{100\}$ faces are formed (Figures $1 \mathrm{~d}$ and $2 \mathrm{~b}, \mathrm{c}$ ). Growth of the $\{111\}$ faces occurs by triangular layers. The layers edges being oriented along the $\{110\}$ directions and the vertices being oriented in the direction 
of $\{100\}$ faces (Figures 1c and 3). The layers form clusters of various configurations, depending on the system composition. Figure 3 shows examples of the microrelief of $\{111\}$ faces from the experiments. In an experiment with Eu oxalate (run ES-8), triangular layers form serrate echelons of macrosteps propagating in one direction (Figure 3a). The terraces of steps are covered with numerous triangular vicinal pyramids, no larger than $10 \mu \mathrm{m}$ in size. The $\{111\}$ faces are composed of large (up to $100 \mu \mathrm{m}$ ) vicinal pyramids with very sloping stepped walls on the diamond grown in aqueous Eu carbonate (Figure $3 \mathrm{~b}$ ). The wall inclination angle of these vicinal pyramids is less than $1^{\circ} . \mathrm{In} \mathrm{EuF}_{3}$ (run ES-12) and $\mathrm{EuCl}_{3}$ (run ES-3) melts, growth of the $\{111\}$ faces occurs at lower rates by echelons of serrate trigonal layers propagating from the edges to the center of the faces (Figure 3c).
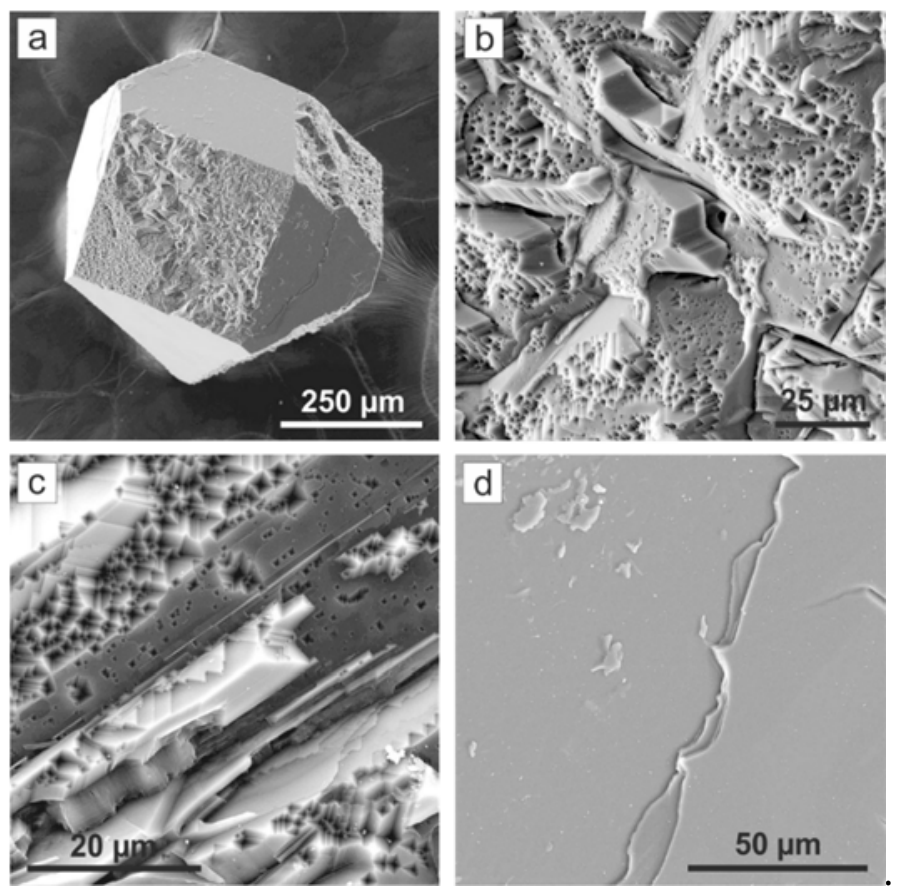

Figure 2. SEM micrographs of diamonds after run with Eu carbonate melt (run ES-6): (a) seed crystal with overgrown diamond layers; (b,c) fragments of $\{100\}$ face; (d) growth layers on the (111) face.

A different pattern is observed in the case of diamond growth in $\mathrm{Eu}^{2+}$ fluoride (run ES-10). The $\mathrm{V}_{(100)} / \mathrm{V}_{(111)}$ ratio in this experiment is 1.33. This rate ratio corresponds to the growth of the octahedron with minor $\{100\}$ faces, which was detected based on the microrelief of faces in this experiment. The $\{100\}$ faces of seed crystals complete growth by patters and meander islets faceted by $\{100\}$ and $\{111\}$ faces (Figure $4 a)$. Diamond growth on the $\{111\}$ faces occurs by hexagonal macrolayers evenly situated across the entire face (Figure 3d).

Metastable graphite, in varying amounts, was present in almost all experiments. The crystallization of graphite in the field of diamond thermodynamic stability as a metastable phase of carbon is a well-known phenomenon in the synthesis of diamond using non-metallic solvent catalysts $[13,17]$. In our experiments, graphite formed intergrowths of plate crystals and grew on seed crystals. Graphite crystallized on seed crystals interacted differently with growing diamond layers, depending on diamond growth rates. In an $\mathrm{Eu}_{2}\left(\mathrm{C}_{2} \mathrm{O}_{4}\right)_{3} \cdot 10 \mathrm{H}_{2} \mathrm{O}$ (run ES-8) melt, a large amount of metastable graphite had no effect on the morphology of diamond layers (Figures 1 and $3 a$ ). As the diamond growth rate in an $\mathrm{Eu}_{2}\left(\mathrm{CO}_{3}\right)_{3} \cdot 3 \mathrm{H}_{2} \mathrm{O}$ melt (run ES-6) decreases, traces of joint growth of metastable graphite and diamond in the form of scars with induction surfaces are clearly seen only on the $\{100\}$ faces (Figure 2b,c). As diamond growth rates further decrease (runs ES-3 and ES-12), metastable graphite crystallizes, together with diamond, on both $\{100\}$ and $\{111\}$ faces. In this case, a large amount of inclusions of hexagonal and rounded graphite plates of up to $3 \mu \mathrm{m}$ in size are found in a diamond 
layer along the $\{111\}$ faces (Figure $4 b$ ). Metastable graphite in the form of independent crystals was not observed only in an experiment on diamond crystallization in EuF 2 melt (run ES-10), where the minimum growth rates were detected. However, the plates of metastable graphite were present as inclusions in diamond layers of $\{111\}$ faces (Figure $4 \mathrm{~b}$ ). Therefore, the identified series of diamond crystallization intensities in europium salt melts: $\mathrm{Eu}_{2}\left(\mathrm{C}_{2} \mathrm{O}_{4}\right)_{3} \cdot 10 \mathrm{H}_{2} \mathrm{O}>\mathrm{Eu}_{2}\left(\mathrm{CO}_{3}\right)_{3} \cdot 3 \mathrm{H}_{2} \mathrm{O}>\mathrm{EuF}_{3}>$ $\mathrm{EuF}_{2}$ is also valid for the metastable graphite crystallization intensity.
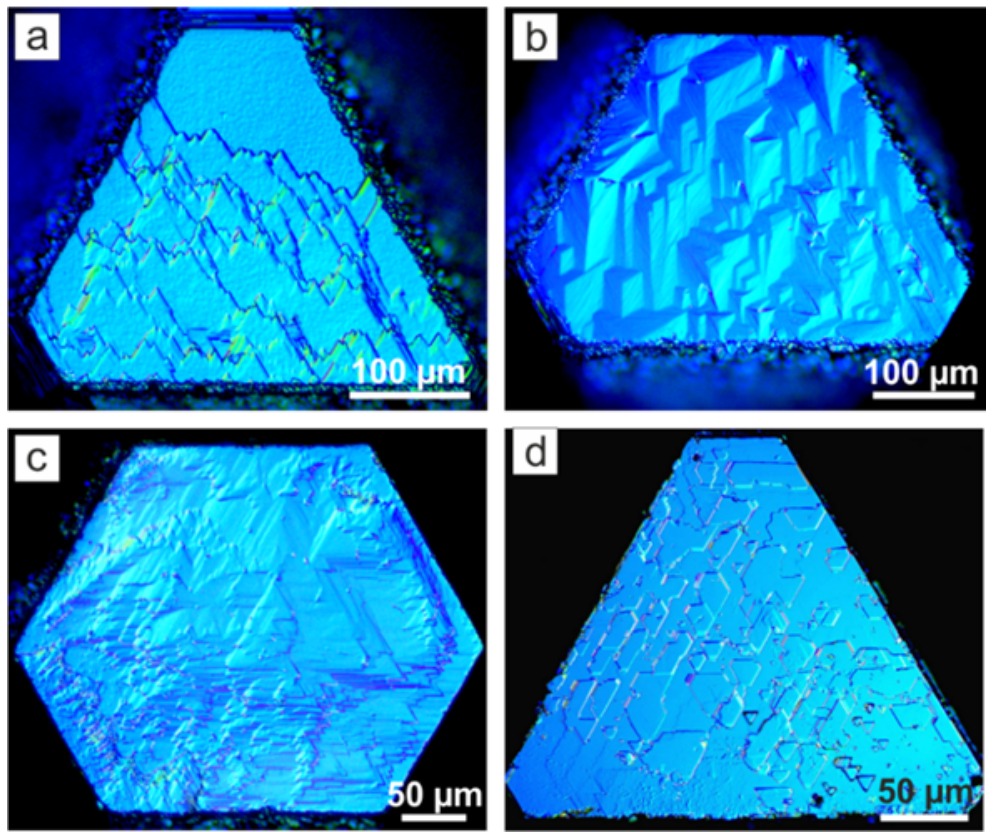

Figure 3. Optical micrographs (differential interference contrast (DIC) method) of the $\{111\}$ faces of diamond seed crystals from experiments in molten europium salts: (a) run ES-8; (b) run ES-6; (c) run ES-12; (d) run ES-10.
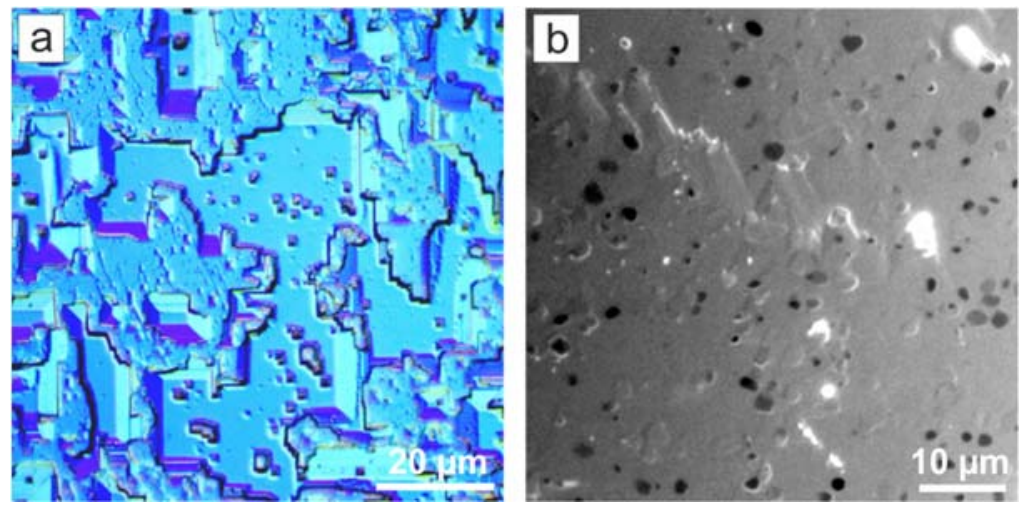

Figure 4. Optical micrographs of fragments of overgrown diamond layers on seed crystals: (a) $\{100\}$ face (run ES-10, DIC metod); (b) inclusions of graphite (black) in overgrown diamond layers (run ES-3, transmitted light).

The highest growth rate of diamond and metastable graphite in experiments with aqueous Eu oxalate can be explained by its instability at experimental parameters. We have not found studies on the stability of aqueous Eu carbonate at high pressure. However, on the basis of the available data at atmospheric pressure, we may suppose that carbonate and oxalate dehydration also occurs at elevated $\mathrm{P}$ and $\mathrm{T}$ parameters. Further, oxalate decomposes to form Eu carbonate, carbon dioxide, and free carbon (graphite). Therefore, diamond crystallization media in these systems were Eu carbonate 
melts with a dissolved water-carbon dioxide fluid and excess carbon (runs ES-7 and ES-8), or with a predominantly water fluid (run ES-6).

A higher intensity of carbon phases (diamond and graphite) crystallization in experiments with starting aqueous oxalate and $\mathrm{Eu}$ carbonate relative to Eu halides correlates with the results of previous studies on diamond crystallization. The diamond growth rates in carbonate systems are significantly higher than the growth rates in halide systems. For example, the degree of graphite to diamond transformation is about $2 \%$ in a $\mathrm{KCl}$ melt at $\mathrm{P}=7.5 \mathrm{GPa}, \mathrm{T}=1800{ }^{\circ} \mathrm{C}$, and $20 \mathrm{~h}$ [13]. The addition of $\mathrm{K}_{2} \mathrm{CO}_{3}$ in an amount of $20 \mathrm{wt} . \%$ leads to the complete transition of all graphite to diamond [13]. It was also previously found that the diamond growth rate in melts of alkali metal halide at $\mathrm{P}=6 \mathrm{GPa}$ and $\mathrm{T}=1620^{\circ} \mathrm{C}$ is about $1 \mu \mathrm{m} / \mathrm{h}$ [16]. The diamond growth rate in the $\mathrm{K}_{2} \mathrm{CO}_{3}+\mathrm{CO}_{2}+\mathrm{C}$ system at close parameters $\left(7.5 \mathrm{GPa}\right.$ and $\left.\mathrm{T}=1700^{\circ} \mathrm{C}\right)$ is $8 \mu \mathrm{m} / \mathrm{h}$ [14]. Even at lower $\mathrm{P}, \mathrm{T}$ parameters, significant diamond growth was observed in melts of alkaline and alkaline earth carbonates $[11-13,18]$.

\subsection{Spectroscopic Characterization}

Infrared absorption measurements were only possible for the aggregates of spontaneously nucleated diamond crystals produced in run ES-8. Due to the polycrystalline structure of the samples and their low thickness $(<50 \mu \mathrm{m})$ the recorded spectra were distorted and showed relatively low signal-to-noise ratios. Nevertheless, identification of the absorption in the defect-induced one phonon-region could be made without difficulties. The observed absorption band peaking at $1280 \mathrm{~cm}^{-1}$ (Figure 5) can unambiguously be assigned to the A aggregates of nitrogen (pairs of nearest-neighbor substitutional nitrogen atoms). After background correction and normalization of the experimental spectrum to the intrinsic multi-phonon absorption of diamond, the concentration of the A-form nitrogen was estimated from the strength of absorption at $1280 \mathrm{~cm}^{-1}$, taking into account that $1 \mathrm{~cm}^{-1}$ absorption at $1280 \mathrm{~cm}^{-1}$ is produced by $16.5 \mathrm{ppm}$ of A-form nitrogen [19]. Our estimations of the nitrogen content gave values of 1000-1200 ppm. Such nitrogen concentrations are much higher than those typical of synthetic diamonds produced from conventional metal-carbon systems (about 200-300 ppm). At the same time, it has been experimentally demonstrated that diamonds synthesized using different non-metallic catalysts may contain very high nitrogen concentrations, up to $1000 \mathrm{ppm}$ and higher, even if the crystallization system was not deliberately doped with nitrogen-containing species [20,21]. The main sources of nitrogen in this case are the nitrogen impurities in the solvent-catalyst and starting graphite, as well as the atmospheric nitrogen in the pore space in the high-pressure cell components. We can therefore conclude that europium oxalate belongs to that type of solvent-catalysts, which promotes nitrogen incorporation into the growing diamond.

The photoluminescence characteristics of spontaneous diamond aggregates from run ES-8 were examined for as-recovered samples and after their treatment in acids. The obtained PL spectra are shown in Figure 6. As-recovered samples exhibited strong luminescence features typical of the $\mathrm{Eu}^{3+}$ ions [22]. The spectrum was dominated by three groups of emission lines centered at approximately 592,615 and $690 \mathrm{~nm}$, which corresponded to the electronic transitions from the ${ }^{5} \mathrm{D}_{0}$ level to the ${ }^{7} \mathrm{~F}_{1}$, ${ }^{7} \mathrm{~F}_{2}$ and ${ }^{7} \mathrm{~F}_{4}$ sublevels, respectively. Note, that all the emission bands of the $\mathrm{Eu}^{3+}$ ion corresponding to the ${ }^{5} \mathrm{D}_{0} \rightarrow{ }^{7} \mathrm{~F}_{\mathrm{J}}(\mathrm{J}=0-6)$ transitions could be identified in the spectrum. The observed strong Eu-related photoluminescence was due to contamination of the diamond aggregates with quenched catalyst melt species, presumably europium carbonate. After the acid treatment of the samples, the photoluminescence intensity decreased by approximately, two orders of magnitude and the PL features observed in the spectrum were several times weaker than the first-order Raman line of diamond. The spectrum showed a band due to the N3 centers (zero-phonon line at $415 \mathrm{~nm}$ and related phonon sideband), a broad band peaking at 520 , whose origin is unclear, and three bands centered at $592 \mathrm{~nm}, 615 \mathrm{~nm}$ and $690 \mathrm{~nm}$, which again can be assigned to the $\mathrm{Eu}^{3+}$ ions. However, in this case, the Eu-related PL bands did not show a fine structure and appeared as a composition of poorly resolved relatively broad peaks. This observation can be explained by supposing that, in this case, the Eu-containing species were entrapped inside the diamond aggregates as inclusions either 
inside diamond crystals or at the intercrystallite boundaries. Similar effects of the broadening of the Eu-related PL lines were recently observed by Sedov et al. [5] for EuF3 nanoparticles imbedded into the polycrystalline CVD diamond matrix.

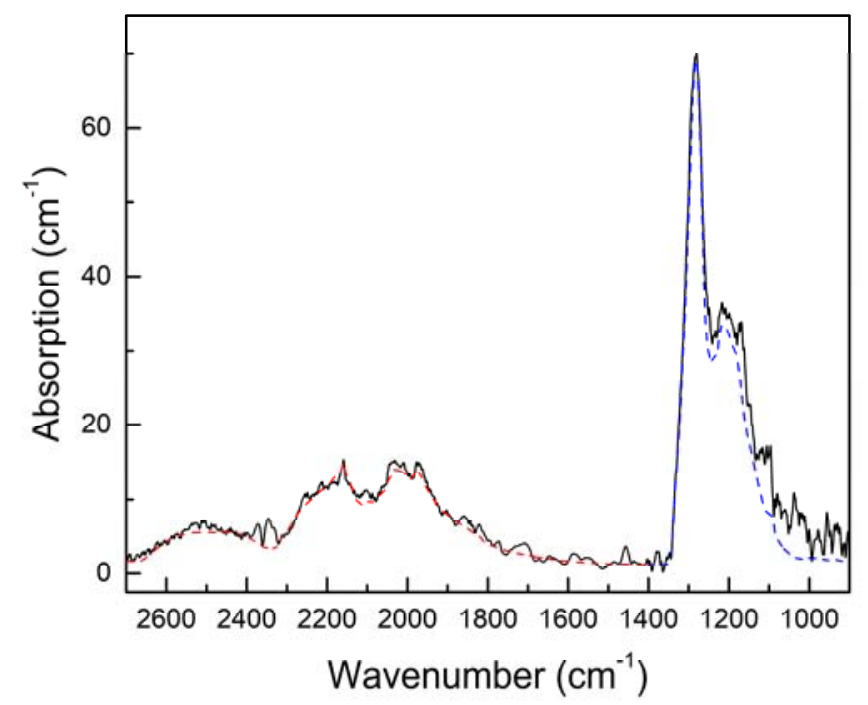

Figure 5. Infrared absorption spectrum of a spontaneous diamond aggregate from run ES-8. Red dashed curve shows standard absorption spectrum of type IIa diamond. Blue dashed curve shows absorption spectrum of A-form nitrogen.

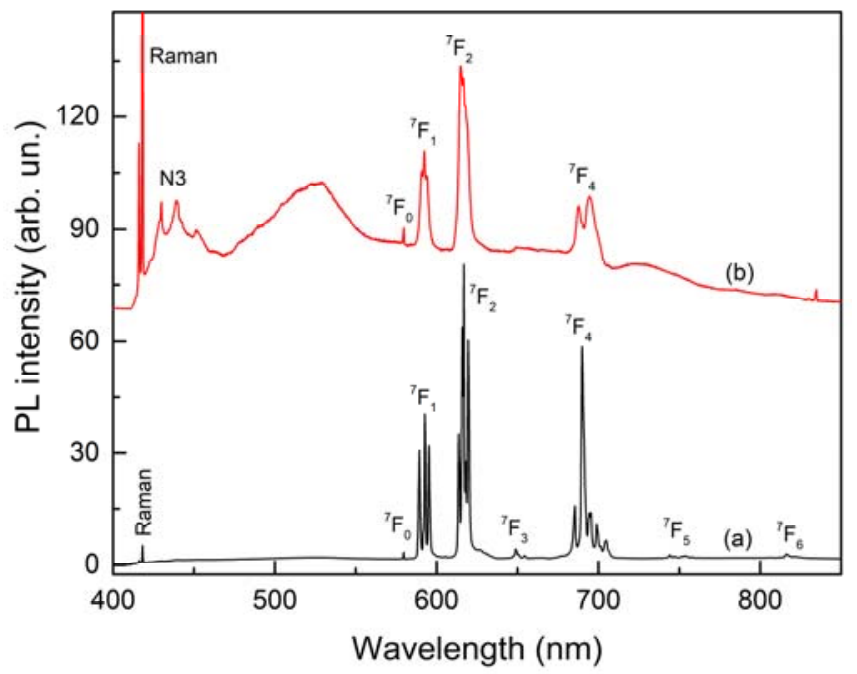

Figure 6. Photoluminescence spectra of a spontaneous diamond aggregate from run ES-8 recorded (a) before and (b) after acid cleaning. PL bands due transitions from the ${ }^{5} \mathrm{D}_{0}$ state to different levels of the ${ }^{7} \mathrm{~F}_{\mathrm{J}}$ state of the $\mathrm{Eu}^{3+}$ ion are marked. The spectra are displaced vertically for clarity.

Attempts to register photoluminescence from the diamond layers grown on the seed crystals in run ES-8 as well as in other runs, where diamond growth was detected, were not successful, due to the low thickness of the layers and a very strong PL signal originating from the seed crystals. Because of the high temperatures, applied in the synthesis experiments, the seed diamond crystals had undergone an annealing process resulting in the formation of a variety of Co- $\mathrm{N}$ and $\mathrm{Ni}-\mathrm{N}$ optical centers [23], which produce bright photoluminescence in the visible range. 


\section{Conclusions}

A study of diamond crystallization in the melts of europium salts at $7.8 \mathrm{GPa}$ showed that at $1800^{\circ} \mathrm{C}$, diamond synthesis and diamond growth on seed crystals do not occur. Diamond growth on seed crystals was realized in all experiments at $2000{ }^{\circ} \mathrm{C}$. The highest growth rate occurred in the europium oxalate melt: $22.5 \mu \mathrm{m} / \mathrm{h}$ on the $\{100\}$ faces and $12.5 \mu \mathrm{m} / \mathrm{h}$ on the $\{111\}$ faces. Additionally, spontaneous diamond crystals were produced in the europium oxalate melt. The diamond formation intensity in the studied systems decreased in the following series: $\mathrm{Eu}_{2}\left(\mathrm{C}_{2} \mathrm{O}_{4}\right)_{3} \cdot 10 \mathrm{H}_{2} \mathrm{O}>\mathrm{Eu}_{2}\left(\mathrm{CO}_{3}\right)_{3} \cdot 3 \mathrm{H}_{2} \mathrm{O}>\mathrm{EuF}_{3}$ $>\mathrm{EuF}_{2}=\mathrm{EuCl}_{3}$. Diamond crystallization occurred in the region of stable octahedral growth in $\mathrm{Eu}^{3+}$ salts melts and in the region of cubo-octahedral growth in $\mathrm{EuF}_{2}$ melt. The microrelief of faces was characterized by specific features, depending on the system composition and diamond growth rate. From the spectroscopic characterization, it was found that diamonds synthesized from Eu oxalate contain relatively high concentrations of nitrogen (about 1000-1200 ppm) and show weak PL features due to inclusions of Eu-containing species.

Thus, the results showed that molten Eu salts are new diamond-producing systems that provide diamond growth on seeds and spontaneous diamond nucleation at $7.8 \mathrm{GPa}$ and $2000{ }^{\circ} \mathrm{C}$. The sequence in the intensity of diamond formation in the studied systems is established. However, the tested systems did not allow the doping of diamond with Eu ions. Perhaps this is due to the doping of diamond crystals with nitrogen in our experiments. Therefore, a further search for new diamond-producing systems, in our opinion, should focus on nitrogen-gettered systems.

Author Contributions: Conceptualization, Y.N.P.; methodology, Y.N.P. and Y.M.B.; investigation, Y.M.B., A.F.K., I.N.K. and D.V.N.; visualization, A.F.K. and Y.N.P.; writing-original draft preparation, A.F.K. and Y.N.P.; writing-review and editing, Y.N.P. and A.F.K. All authors have read and agreed to the published version of the manuscript.

Funding: This research was funded by the Russian Foundation for Basic Research, grant number 18-29-12041, and the Ministry of Science and Higher Education of the Russian Foundation on state assignment of IGM SB RAS.

Conflicts of Interest: The authors declare no conflict of interest. The funders had no role in the design of the study; in the collection, analyses, or interpretation of data; in the writing of the manuscript, or in the decision to publish the results.

\section{References}

1. Kenyon, A.J. Recent developments in rare-earth doped materials for optoelectronics. Prog. Quantum Electron. 2002, 26, 225-284. [CrossRef]

2. Zhong, M.; Hedges, M.P.; Ahlefeldt, R.L.; Bartholomew, J.G.; Beavan, S.E.; Wittig, S.M.; Longdell, J.J.; Sellarset, M.J. Optically addressable nuclear spins in a solid with a six-hour coherence time. Nature 2015, 517, 177-180. [CrossRef] [PubMed]

3. Magyar, A.; Hu, W.; Shanley, T.; Flatte, M.E.; Hu, E.; Aharonovich, I. Synthesis of luminescent europium defects in diamond. Nat. Commun. 2014, 5, 3523. [CrossRef] [PubMed]

4. Vanpoucke, D.E.P.; Nicley, S.S.; Raymakers, J.; Maes, W.; Haenen, K. Can europium atoms form luminescent centers in diamond: A combined theoretical-experimental study. Diam. Relat. Mater. 2019, 94, $233-241$. [CrossRef]

5. Sedov, V.S.; Kuznetsov, S.V.; Ralchenko, V.G.; Mayakova, M.N.; Krivobok, V.S.; Savin, S.S.; Zhuravlev, K.P.; Martyanov, A.K.; Romanishkin, I.D.; Khomich, A.A.; et al. Diamond-EuF3 nanocomposites with bright orange photoluminescence. Diam. Relat. Mater. 2017, 72, 47-52. [CrossRef]

6. Ekimov, E.A.; Zibrov, I.P.; Malykhin, S.A.; Khmelnitskiy, R.A.; Vlasov, I.I. Synthesis of diamond in double carbon-rare earth element systems. Mater. Lett. 2017, 193, 130-132. [CrossRef]

7. Khokhryakov, A.F.; Borzdov, Y.M.; Kupriyanov, I.N. High-Pressure Diamond Synthesis in the Presence of Rare-Earth Metals. J. Cryst. Growth 2020, 531, 125358. [CrossRef]

8. Palyanov, Y.N.; Borzdov, Y.M.; Khokhryakov, A.F.; Kupriyanov, I.N. Effect of rare-earth element oxides on diamond crystallization in Mg-based systems. Crystals 2019, 9, 300. [CrossRef] 
9. Palyanov, Y.N.; Borzdov, Y.M.; Kupriyanov, I.N.; Khokhryakov, A.F.; Nechaev, D.V. Diamond crystallization from Mg-C system under high pressure, high temperature conditions. CrystEngComm 2015, 17, 4928-4936. [CrossRef]

10. Palyanov, Y.N.; Kupriyanov, I.N.; Khokhryakov, A.F.; Borzdov, Y.M. High-pressure crystallization and properties of diamond from magnesium-based catalysts. CrystEngComm 2017, 19, 4459-4475. [CrossRef]

11. Palyanov, Y.N.; Sokol, A.G.; Borzdov, Y.M.; Khokhryakov, A.F.; Sobolev, N.V. Diamond formation from mantle carbonate fluid. Nature 1999, 400, 417-418. [CrossRef]

12. Pal'yanov, Y.N.; Sokol, A.G.; Borzdov, Y.M.; Khokhryakov, A.F. Fluid-bearing alkaline carbonate melts as the medium for the formation of diamond in the Earth's mantle: An experimental study. Lithos 2002, 60, 145-159. [CrossRef]

13. Palyanov, Y.N.; Shatsky, V.S.; Sobolev, N.V.; Sokol, A.G. The role of mantle ultrapotassic fluids in diamond formation. Proc. National Acad. Sci. USA 2007, 104, 9122-9127. [CrossRef] [PubMed]

14. Palyanov, Y.N.; Kupriyanov, I.N.; Sokol, A.G.; Borzdov, Y.M.; Khokhryakov, A.F. Effect of $\mathrm{CO}_{2}$ on crystallization and properties of diamond from ultra-alkaline carbonate melt. Lithos 2016, 265, 339-350. [CrossRef]

15. Sokol, A.G.; Borzdov, Y.M.; Palyanov, Y.N.; Khokhryakov, A.F. High-temperature calibration of a multi-anvil high pressure apparatus. High Press. Res. 2015, 35, 139-147. [CrossRef]

16. Wang, Y.; Kanda, H. Growth of HPHT diamonds in alkali halides: Possible effects of oxygen contamination. Diam. Relat. Mater. 1998, 7, 57-63. [CrossRef]

17. Sokol, A.G.; Pal'yanov, Y.N. Diamond crystallization in fluid and carbonate-fluid systems under mantle P-T conditions: 2. An analytical review of experimental date. Geochem. Int. 2004, 42, 1018-1032.

18. Sokol, A.G.; Borzdov, Y.M.; Palyanov, Y.N.; Khokhryakov, A.F.; Sobolev, N.V. An experimental demonstration of diamond formation in the dolomite-carbon and dolomite-fluid-carbon systems. Eur. J. Mineral. 2001, 13, 893-900. [CrossRef]

19. Boyd, S.R.; Kiflawi, I.; Woods, G.S. The relationship between infrared absorption and the A defect concentration in diamond. Phil. Mag. B 1994, 69, 1149-1153. [CrossRef]

20. Kanda, H.; Akaishi, M.; Yamaoka, S. Synthesis of diamond with highest nitrogen concentration. Diam. Relat. Mater. 1999, 8, 1441-1443. [CrossRef]

21. Palyanov, Y.N.; Bataleva, Y.V.; Sokol, A.G.; Borzdov, Y.M.; Kupriyanov, I.N.; Reutsky, V.N.; Sobolev, N.V. Mantle-slab interaction and redox mechanism of diamond formation. Proc. National Acad. Sci. USA 2013, 110, 20408-20413. [CrossRef] [PubMed]

22. Binnemans, K. Interpretation of europium (III) spectra. Coord. Chem. Rev. 2015, 295, 1-45. [CrossRef]

23. Yelisseyev, A.; Kanda, H. Optical centers related to $3 \mathrm{~d}$ transition metals in diamond. New Diam. Front. Carbon Technol. MYU Tokyo 2007, 17, 127-178. 